\title{
Perjanjian TRIPs dan Beberapa Isu Strategis (TRIPs Agreement and Several Strategic Issues)
}

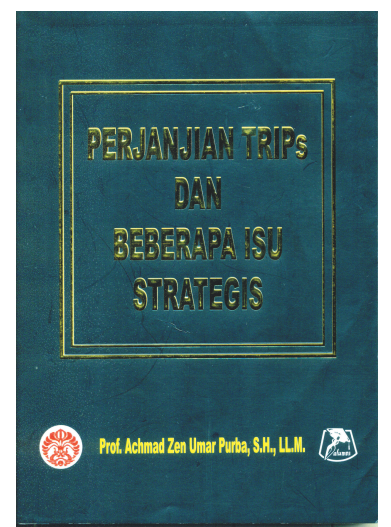

Intellectual Property Rights is one of the most important aspects of foreign investment. Although intellectual property rights is a key element in the TRIPs Agreement, but this book does not discuss the specifics of Intellectual Property Rights (hereinafter referred to as IPR) itself. This book also addresses three other strategic issues in addition to IPR, which are transfer of technology, Traditional Knowledge and Genetic Resources Folklore (SGPTF), and TRIPS Plus. In addition, the book also discusses the relation between TRIPs and the developing countries, especially Indonesia, and also its relation to developed countries.

This book describes the conflict between the "northern states" which the majority of the group are developed countries, and the "southern states" which predominantly consist of developing countries. Indonesia, as a developing country, needs foreign investment to explore natural resources. However, gaining foreign investment is not the main objective. Foreign investment exist to support the development, and to accelerate selfreliance, especially in terms of the transfer of technology. Developing countries that are rich in natural resources are usually in contrast of the unwealthiness of its people. One major factor is because the country does not have a qulified technology and a low number of patent. The author also considered that the concept of transfer of technology in TRIPs is not well designed even if it is not the basic principles and objectives of the TRIPs itself. Therefore, the author argue that transfer of technology is supposed to be the main correlation of an international treaty. This issue is discussed as the first strategic issues in this book.

Genetic source of Traditional Knowledge and Expressions of Folklore (hereinafter abbreviated SGPTF) is the second strategic issues which is discussed and should be taken seriously. This SGPTF face a conflict between the "Northern States" and "Southern States". Northern states argued that the absence of biopiracy as alleged by the Southern states is already protected by the provisions contained in TRIPs. Hence, the developing countries propose a revision of TRIPs intensively through various international forums, especially through the WIPO and the WTO. In practice, not all developing countries adjust the national legislation in the field of intellectual property rights. India has incorporated the requirements of openness (disclosure requirements) in patent law. Indonesia itself is still waiting for the bill on genetic resources, traditional knowledge and traditional cultural expressions.

TRIPs Plus is the third strategic issues discussed in this book. This is a concept imported from developed countries especially the United States (U.S.). In this concept, certain countries might have made a more stringent provision through bilateral agreement by free trade agreement. 
In general, the systematics of this book are as follows: The first chapter of this book is an introduction to the overall review of the book. This chapter emphasized the problems associated with the TRIPs Agreement. The second chapter in this book discusses the trade aspects of intellectual property rights. In this chapter also discussed various verdicts related to the TRIPs Agreemenet. This chapter starts from the opening of TRIPs; substance content of TRIPs; and other issues such as the determination of the court and other aspects of law enforcement. The third chapter in this book discuss mainly about the transfer of technology in relation to foreign investment. The fourth chapter in the book is divided into two major chapters, which are SGPTF as the strategic issues and the enforceability of international regulations. This chapter also discussed conventions and protocols both in international and regional scope such as ASEAN.

Both discussed the issue of TRIPs Plus which aims to develop the concept of minimum provisions contained in TRIPs. This, in addition, is a strategic impact for the concept of intellectual property rights generally. This chapter also raises criticism from various experts. TRIPs Plus concept can primarily affect the accommodation of more stringent standards of TRIPs on the minimum provisions in the TRIPs. TRIPs Plus concept is enforced primarily by the United States through bilateral agreements with developing countries. Finally, the conclusion in this book is consisted in the fifth chapter of the book.

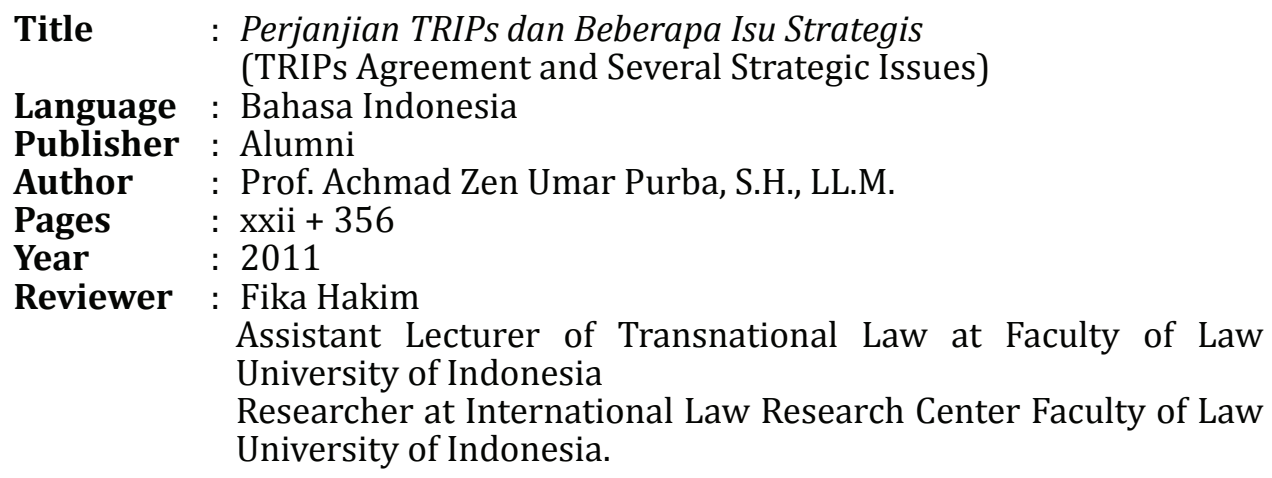

